Revista de MATEMÁticA: TeORÍA y APliCACIONEs 2018 25(2) : 261-292

CIMPA - UCR ISSN: 1409-2433 (PRINT), 2215-3373 (ONLINE)

DOI: https://doi.org/10.15517/rmta.v25i2.33625

\title{
MODELO PARA EL CONTROL ÓPTIMO DEL VIH CON TASA DE INFECCIÓN DEPENDIENTE DE LA DENSIDAD DEL VIRUS
}

\author{
HIV OPTIMAL CONTROL MODEL WITH \\ INFECTION RATE DEPENDING \\ ON THE VIRUS DENSITY \\ HERNÁN DARÍO TORO-ZAPATA* \\ CARLOS ANDRÉS TRUJILlO-SALAZAR ${ }^{\dagger}$
}

Received: 4/Aug/2017; Revised: 6/Mar/2018;

Accepted: 2/May/2018

Revista de Matemática: Teoría y Aplicaciones is licensed under a Creative Commons
Reconocimiento-NoComercial-Compartirigual 4.0 International License.
Creado a partir de la obra en http://www.revistas.ucr.ac.cr/index.php/matematica

${ }^{*}$ Licenciatura en Matemáticas, Universidad del Quindío, Quindío, Colombia. E-Mail: hdtoro@uniquindio.edu.co

${ }^{\dagger}$ Misma dirección que/Same address as: H.D. Toro. E-Mail: catrujillo@uniquindio.edu.co 


\title{
Resumen
}

Se propone un modelo en ecuaciones diferenciales ordinarias para describir la dinámica de infección por VIH en una población de células T CD4 susceptibles a la infección y considerando una tasa de infección no lineal densodependiente. Se analiza la estabilidad del modelo con base en el número básico de reproducción, lo que permite determinar resultados de estabilidad y un umbral de control mediante la reducción de la tasa máxima de infección. Luego se formula un problema de control óptimo para establecer funciones óptimas de tratamiento mediante inhibidores de transcriptasa inversa e inhibidores de proteasa, que minimicen la carga viral y los costos directos y/o indirectos de la administración del tratamiento. Se estudian los casos en que la efectividad del tratamiento es nula y plena, y para el caso de efectividad imperfecta del tratamiento se acude al Principio del Máximo de Pontryagin. Se presentan simulaciones numéricas del modelo sin tratamiento y de los diferentes escenarios con tratamiento.

Palabras clave: sistemas dinámicos; estabilidad; control óptimo; principio del máximo de Pontryagin; VIH; terapia antirretroviral.

\begin{abstract}
We propose a model on ordinary differential equations to describe the dynamics of HIV infection in a population of CD4 T cells susceptible to infection and considering a nonlinear infection rate depending on viral density. The stability of the model is analyzed based on the basic reproduction number, which allows us to determine stability results and a control threshold by reducing the rate of maximum infection. An optimal control problem is then formulated to establish optimal treatment functions by reverse transcriptase inhibitors and protease inhibitors that minimize viral load and direct and/or indirect costs of treatment administration. We study the cases in which the effectiveness of the treatment is null and full, and for the case of imperfect effectiveness of the treatment, we refer to the Maximum Principle of Pontryagin. Numerical simulations of the model without treatment and of the different scenarios with treatment are presented.
\end{abstract}

Keywords: dynamic system; stability; optimal control; Pontryagin maximum principle; HIV; antirretroviral therapy.

Mathematics Subject Classification: 93C15, 49J15, 92B05, 92C50. 


\section{Introducción}

El VIH es reconocido como el agente etiológico o causal del Síndrome de Inmunodeficiencia Adquirida (SIDA); es un virus ARN que pertenece a la familia de los retrovirus del género lentivirus, los cuales tienen largos periodos de incubación. El VIH se diferencia de los demás lentivirus porque tiene 9 genes en su genoma y por lo tanto, es más complejo que los otros que solo tienen tres genes. La variabilidad antigénica y sus constantes mutaciones le sirven al virus para evitar la respuesta inmune del cuerpo, por otro lado, dificulta el desarrollo de una vacuna. El término retrovirus hace referencia a que estos virus requieren retrotranscribir su cadena de ARN a ADN para que su material pueda ser reconocido por el genoma de la célula [11, 31, 25, 44].

El VIH ingresa al organismo por contacto sexual sin protección o por el intercambio de fluidos a través de las mucosas. Una vez que ingresa, el ciclo de infección empieza cuando el virus ataca una célula T CD4 susceptible, una vez que se encuentra dentro de esta, el genoma del VIH es transcrito en cadenas de ADN mediante la intervención de la transcriptasa inversa. La doble cadena de ADN resultante entra en el núcleo junto con la integrasa, la cual es la encargada de incorporarlo en el genoma de la célula. Tras la activación inmunológica de la célula infectada, el ADN viral (llamado provirus) es transcrito en ARN mensajero, usado para la producción de nuevas proteínas y enzimas virales. El ARN viral se mantiene como copias completas para ser incorporado como material genético para la producción de nuevos viriones [3, 4, 21].

La bilbliografía alrededor del modelado del VIH y el SIDA es amplia. Algunos modelos planteados en la literatura se han enfocado en el modelado de la infección y el tratamiento [1, 7, 8, 10, 11, 13, 14, 38, 46, 48, 49, 51, 57, 59, 62]; en el modelado de costos $[19,40,58,62]$; el modelado de la dinámica del VIH $[12,17,26,32,47,52,53]$ o han hecho uso de los procesos estocásticos para modelar la dinámica del VIH/SIDA [9, 12, 17, 23, 26, 32, 47, 48].

En este artículo nos enfocamos en proponer un modelo basado en ecuaciones diferenciales ordinarias, para describir la dinámica de infección por VIH en una población de células T CD4 susceptibles a la infección, y considerando una tasa de infección no lineal densodependiente. En la sección 2 se formula y analiza el modelo, en la sección 3 se formula un problema de control con base en la aplicación de antirretrovirales y finalmente, en la sección 4 se muestran las conclusiones del trabajo. 


\section{El modelo}

\subsection{Formulación de modelo}

Se pretende formular un modelo basado en las dinámicas clásicas de PresaDepredador y Parásito-Hospedero, al suponer que un incremento en las partículas virales depende de forma directa de las células T CD4 que resultan infectadas y posteriormente mueren, concepto que es denominado en esos contextos como conversión de biomasa, y que en este trabajo describe el beneficio reproductivo que el virus obtiene de infectar las células T CD4 del sistema inmune de una persona; consideración que es justificada por la alta tasa de replicación del virus, pero que lleva a asumir que las células infectadas se activan instantáneamente y son productoras de partículas virales, simplificaciones que ya han sido consideradas en trabajos como $[25,29,30]$ y otros citados allí y que permiten que no se considere una variable explícita para la población de células infectadas.

Sea $T=T(t)$ el número promedio de células T CD4 en un tiempo $t$ y asuma que las células se incrementan a una tasa constante $\sigma$ y que mueren en proporción a su tamaño con tasa de muerte natural $\mu$, por lo tanto, el número promedio de células que mueren en un tiempo $t$ está dado por $\mu T$. Lo que en ausencia de virus conlleva a la ecuación diferencial,

$$
\dot{T}=\sigma-\mu T .
$$

En este caso, las células T CD4 alcanzan el nivel de equilibrio $\sigma / \mu[44,55]$. En efecto, la ecuación para $T$ es lineal y tiene por solución particular la función

$$
T(t)=\frac{\sigma}{\mu}+\left(T(0)-\frac{\sigma}{\mu}\right) e^{-\mu t}
$$

de donde $T(t) \rightarrow \frac{\sigma}{\mu}$ cuando $t \rightarrow \infty$ y $T(0)$ es la condición inicial.

Sea $V=V(t)$ la concentración promedio del VIH en un tiempo $t$ y considere que cuando el virus ingresa en el organismo, ataca estas células $T$ produciendo la infección y la correspondiente replicación viral. Suponga que la tasa de infección está dada por la expresión $f(V) T$, usualmente considerada de forma bilineal, es decir, de la forma $\beta T V$, asumiendo que se satisface la ley de acción de masas, como puede verse en múltiples trabajos tales como $[1,7,9,11,12,14,25,23,26,38,41,43,44,42,46,47,49,51,54,55,60]$. Sin embargo, la ley de acción de masas tiene algunas características consideradas poco realistas, en particular que el número de células recién infectadas producidas por un solo virus depende de las células $T$ y llega a ser muy alta cuando esta población es grande. Algunos autores utilizan una tasa de infección saturada (dependiente de la densidad del virus) para eliminar esa característica 
(en particular se recomienda ver [5, 25, 29, 30, 36] y las referencias allí); es decir, que se describe mediante una tasa de infección funcional, en particular la respuesta funcional Holling tipo II, la respuesta funcional de BeddingtonDeAngelis, y otras más sofisticadas que pueden encontrarse en $[5,61,60]$. Suponga entonces que la tasa de infección entre células $T$ y el virus $V$ crece rápidamente cuando la concentración promedio del VIH es pequeña, y luego crece más lentamente cuando $V$ es más grande, hasta alcanzar cierta tasa máxima de infección $\beta$ $[1,6,22,25,28,29,34,37]$, lo que puede describirse por la expresión,

$$
f(V)=\frac{\beta V}{k+V} .
$$

En donde $k$ es la tasa de saturación media, es decir, el número promedio de partículas virales necesario para alcanzar la tasa de infección media $\beta / 2$, como puede apreciarse en la Figura 1. Con esta consideración, la ecuación que describe la variación de las células $T$ tras la infección queda de la forma:

$$
\dot{T}=\sigma-\frac{\beta V T}{k+V}-\mu T \text {. }
$$

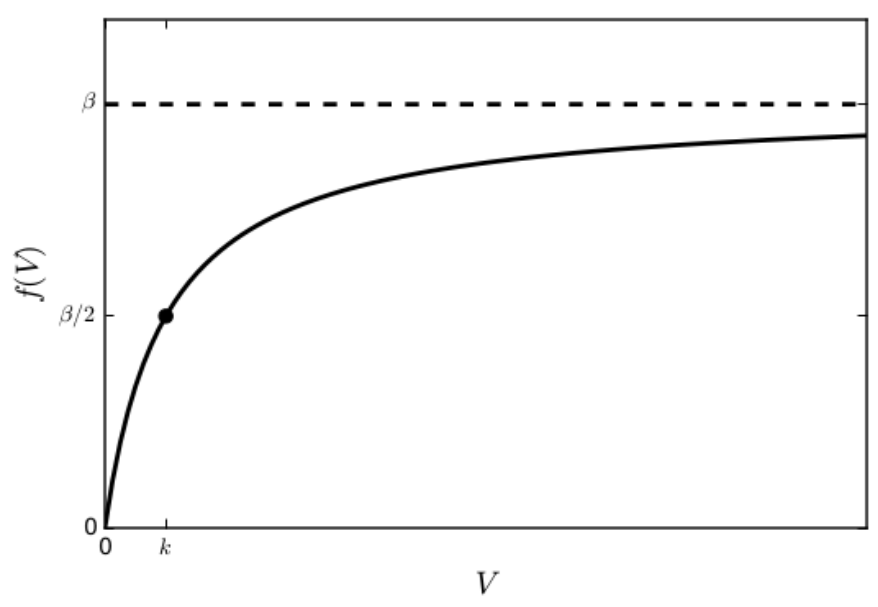

Figura 1: Tasa de contactos entre células $T$ y virus $V$ con saturación $f(V)=\frac{\beta V}{k+V}$. Observe que esta tasa de infección se satura cuando la población de virus es muy grande.

Como en este trabajo no se considera una variable explícita para la población de células infectadas; entonces se asume que las células infectadas se activan inmediatamente tras la infección iniciando la replicación viral, y que a su muerte 
liberan grandes cantidades de partículas virales, proceso que ocurre continuamente en el organismo de una persona infectada, y por lo cual no se considera de manera explícita una categoría para las células $T$ infectadas [25]. Asumiendo que la tasa de muerte relacionada con el virus de las células infectadas es $\delta$, entonces en un tiempo $t$ muere una proporción $\delta$ de las células que se infectan $\frac{\beta V T}{k+V}$. Adicionalmente, si $N$ describe la tasa de producción viral de cada célula infectada, entonces se producen en cada $t$ un promedio de $N \delta\left(\frac{\beta V T}{k+V}\right)$ partículas virales. Finalmente, las partículas virales son eliminadas a una tasa de proporcionalidad $c$, lo que lleva a la ecuación que describe la variación de las partículas virales,

$$
\dot{V}=\frac{N \delta \beta V T}{k+V}-c V
$$

Note que el producto $N \delta$ que aparece en la ecuación para $V$, determina la medida en que el virus se beneficia reproductivamente de las células $T$. De acuerdo con lo anterior, las ecuaciones (1) y (2) conforman el sistema que describe la dinámica, el cual toma la forma,

$$
\left\{\begin{array}{l}
\dot{T}=\sigma-\frac{\beta V T}{k+V}-\mu T \\
\dot{V}=\frac{N \delta \beta V T}{k+V}-c V .
\end{array}\right.
$$

Con condiciones iniciales $T(0)=T_{0}$ y $V(0)=V_{0}$, donde los parámetros $\sigma, k, \mu, N, \delta, \beta, \mathrm{y} c$ son positivos. Una descripción completa de los parámetros del modelo, de los valores asignados para las simulaciones numéricas, así como algunas fuentes bibliográficas usadas, se encuentra en la Tabla 1.

Proposición 2.1 La región $\Omega=\left\{(T, V) \in \mathbb{R}^{2}: 0 \leq T \leq \frac{\sigma}{\mu}, 0 \leq V \leq \frac{N \beta \delta \sigma}{c \mu}\right\}$ es un conjunto positivamente invariante para el sistema (3).

Demostración. En efecto,

$$
\left.\dot{T}\right|_{T=0}=\sigma>0,\left.\quad \dot{V}\right|_{V=0}=0 .
$$

Lo que garantiza la no negatividad de las soluciones. Para mostrar que las soluciones están acotadas superiormente, basta observar que:

$$
\dot{T}=\sigma-\frac{\beta V T}{k+V}-\mu T \leq \sigma-\mu T .
$$

De donde se tiene que $T(t) \leq \frac{\sigma}{\mu}\left(1-e^{-\mu t}\right)$ y de este modo $T(t) \leq \frac{\sigma}{\mu}$, para $t \rightarrow \infty$. Por otro lado, se sabe que $\frac{\beta V}{k+V}<\beta$, para todo $V$, entonces

$$
\dot{V}=\frac{N \delta \beta V T}{k+V}-c V \leq N \delta \frac{\beta V}{k+V} \frac{\sigma}{\mu}-c V \leq N \delta \beta \frac{\sigma}{\mu}-c V .
$$


Tabla 1: Descripción de parámetros y valores usados en la simulación, con su respectiva referencia.

\begin{tabular}{c|llc}
\hline \hline Símb & Descripción & Valor & Referencia \\
\hline$T_{0}$ & Valor inicial de las células T CD4 & $1000 \mathrm{~mm}^{-3}$ & {$[43]$} \\
$V_{0}$ & Carga viral inicial & $10^{-3} \mathrm{~mm}^{-3}$ & {$[43]$} \\
$\sigma$ & Producción constante de células T CD4 & $10 \mathrm{~mm}^{-3} \mathrm{~d}^{-1}$ & {$[5,11,38,43]$} \\
$\beta$ & Tasa máxima de infección de las células T & 0.16036 & {$[11]$} \\
& CD4 & & \\
$\mu$ & Tasa de muerte natural de las T CD4 no in- & $0.01 \mathrm{~d}^{-1}$ & {$[1,5,46]$} \\
& fectadas & & \\
$\delta$ & Tasa de muerte de las T CD4 infectadas por & $0.26 \mathrm{~d}^{-1}$ & {$[11]$} \\
$N$ & efecto del virus & & \\
$c$ & Tasa de producción viral & $2500 \mathrm{cel}^{-1}$ & {$[5,41]$} \\
$k$ & Tasa de eliminación del virus & $2.5 \mathrm{~d}^{-1}$ & {$[60]$} \\
$A$ & Tasa de saturación media & 5000 & {$[28]$} \\
$B$ & Ponderador del tratamiento por ITI & 3000 & Ad hoc \\
$\epsilon$ & Ponderador del tratamiento por ITI & 3000 & Ad hoc \\
& Tolerancia al error en la simulación del & $10^{-5}$ & Ad hoc \\
$\tau$ & problema de contorno & & Ad hoc \\
\hline \hline
\end{tabular}

Con lo cual se tiene que $V(t) \leq \frac{N \delta \beta \sigma}{c \mu}\left(1-e^{-c t}\right)$ y, por lo tanto, $V(t) \leq \frac{N \delta \beta \sigma}{c \mu}$, cuando $t \rightarrow \infty$. En conclusión, todas las soluciones con condiciones iniciales positivas se mantendrán positivas y acotadas en $\Omega$ para $t \rightarrow \infty$. La prueba anterior está basada en procedimientos usuales en este tipo de sistemas; en particular, para el contexto de sistemas de ecuaciones diferenciales ordinarias que modelan la infección por VIH, se recomienda al lector revisar $[43,56,61]$.

El conjunto $\Omega$ es una región con sentido biológico para el modelo (3), ya que establece que las poblaciones no se hacen negativas ni crecen sin cota.

\subsection{Análisis de estabilidad del modelo}

El sistema (3) cuenta con dos soluciones estacionarias o puntos de equilibrio $E_{0}$ y $E_{1}$, que corresponden al equilibrio en ausencia de infección y al equilibrio en presencia del virus, respectivamente. Tales soluciones están dadas explícitamente por, 


$$
\begin{aligned}
& E_{0}=\left(\frac{\sigma}{\mu}, 0\right), \\
& E_{1}=\left(\frac{N \delta \sigma+c k}{N \delta(\beta+\mu)}, \frac{N \beta \delta \sigma-c k \mu}{(\beta+\mu) c}\right) .
\end{aligned}
$$

Para garantizar que $E_{1}$ se encuentre en la región $\Omega$ y tenga sentido su estudio, se debe cumplir que $\frac{N \beta \delta \sigma-c k \mu}{(\beta+\mu) c}>0$, lo que es equivalente a tener $\frac{k \mu}{(\beta+\mu)}\left(\frac{N \beta \delta \sigma}{c k \mu}-1\right)>0$, expresión a partir de la cual se define el siguiente umbral

$$
R_{0}=\frac{N \beta \delta \sigma}{c k \mu},
$$

el cual corresponde al número básico de reproducción y determina el número medio de infecciones secundarias causadas por una única célula T CD4 infectada en una población de células T CD4 totalmente susceptible, a lo largo de su periodo infeccioso, cuya forma e interpretación coincide con la descrita en [23], específicamente para modelos de la infección por VIH, y con la definición clásica de la Epidemiología y la Ecología.

Proposición 2.2 Si $R_{0} \leq 1$ entonces el sistema (3) tiene un único equilibrio $E_{0}$ en $\Omega$. Y si $R_{0}>1$ entonces el sistema (3) tiene dos equilibrios $E_{0}$ y $E_{1}$ en $\Omega$.

Demostración. Se empieza por reexpresar $E_{1}$ de la siguiente manera:

$$
E_{1}=\left(\frac{\sigma}{\beta+\mu}+\frac{c k}{N \delta(\beta+\mu)}, \frac{k \mu}{(\beta+\mu)}\left(\frac{N \beta \delta \sigma}{c k \mu}-1\right)\right) .
$$

Al considerar $R_{0}=1$, que es equivalente a $\frac{N \beta \delta \sigma}{c k \mu}=1$, se anula la segunda componente de $E_{1}$ y teniendo en cuenta que

$$
\frac{N \beta \delta \sigma}{\mu}=c k
$$

entonces $E_{1}$ adopta la siguiente forma

$$
\begin{aligned}
E_{1} & =\left(\frac{\sigma}{\beta+\mu}+\frac{N \beta \delta \sigma}{N \delta \mu(\beta+\mu)}, 0\right) \\
& =\left(\frac{N \delta \sigma \mu+N \beta \delta \sigma}{N \delta \mu(\beta+\mu)}, 0\right) \\
& =\left(\frac{N \delta \sigma(\beta+\mu)}{N \delta \mu(\mu+\beta)}, 0\right) \\
& =\left(\frac{\sigma}{\mu}, 0\right) .
\end{aligned}
$$


Luego, $E_{1}=E_{0}$. Por otro lado, considerar $R_{0}<1$ es equivalente a tener $\frac{N \beta \delta \sigma}{c k \mu}<1$, lo que hace negativa a la segunda componente de $E_{1}$, que de este modo pierde su sentido biológico. En conclusión, si $R_{0}=1$ o $R_{0}<1$, el único punto de equilibrio es $E_{0}$.

Nótese que $E_{0}$ se encuentra exactamente sobre la frontera de $\Omega$, sin que esto dependa de $R_{0}$. Por lo tanto, para demostrar la segunda implicación, basta con mostrar que si $R_{0}>1$ entonces las componentes de $E_{1}$ están acotadas como se indica en la región $\Omega$. En efecto, para la primera componente se tiene lo siguiente

$$
\begin{aligned}
R_{0} & >1 \\
\frac{N \beta \delta \sigma}{c k \mu} & >1 \\
N \beta \delta \sigma & >c k \mu \\
N \beta \delta \sigma+N \delta \sigma \mu & >N \delta \sigma \mu+c k \mu \\
N \delta \sigma(\beta+\mu)+ & >\mu(N \delta \sigma+c k) \\
\frac{\sigma}{\mu} & >\frac{N \delta \sigma+c k}{N \delta(\beta+\mu)} .
\end{aligned}
$$

Para la segunda componente de $E_{1}$ se parte del siguiente hecho $R_{0}>1$ implica que $R_{0}>-\frac{\mu}{\beta}$. Luego

$$
\begin{aligned}
\beta R_{0} & >-\mu \\
\beta R_{0}+\mu R_{0} & >\mu R_{0}-\mu \\
(\beta+\mu) R_{0} & >\mu\left(R_{0}-1\right) \\
R_{0} & >\frac{\mu}{\beta+\mu}\left(R_{0}-1\right) \\
\frac{N \beta \delta \sigma}{c k \mu} & >\frac{\mu}{\beta+\mu}\left(\frac{N \beta \delta \sigma}{c k \mu}-1\right) \\
\frac{N \beta \delta \sigma}{c \mu} & >\frac{k \mu}{\beta+\mu}\left(\frac{N \beta \delta \sigma}{c k \mu}-1\right) .
\end{aligned}
$$

Proposición 2.3 El equilibrio trivial $E_{0}$ del sistema (3) es local y asintóticamente estable si y solo si $R_{0}<1$.

Demostración. La matriz jacobiana del sistema (3) está dada por,

$$
J=\left[\begin{array}{cc}
-\frac{\beta V}{k+V}-\mu & -\frac{\beta T}{k+V}+\frac{\beta T V}{(k+V)^{2}} \\
\frac{N \delta \beta V}{k+V} & \frac{N \delta \beta T}{k+V}+\frac{N \delta \beta T V}{(k+V)^{2}}-c
\end{array}\right] .
$$

Al evaluarla en el equilibrio trivial se tiene,

$$
J_{0}=\left[\begin{array}{cc}
-\mu & -\frac{\beta \sigma}{\mu k} \\
0 & c\left(R_{0}-1\right)
\end{array}\right]
$$


cuyos valores propios son $\lambda_{1}=-\mu \mathrm{y} \lambda_{2}=c\left(R_{0}-1\right)$ y en consecuencia, $R_{0}<1$, es condición necesaria y suficiente para que $\lambda_{2}<0$ y por lo tanto, para que el equilibrio trivial $E_{0}$ sea local y asintóticamente estable.

Como consecuencia directa de la Proposición 2.3 se tiene que si $R_{0}>1$ el valor propio $\lambda_{2}$ es positivo y en consecuencia el equilibrio $E_{0}$ es inestable.

Proposición 2.4 Dado $R_{0} \leq 1$, el equilibrio trivial $E_{0}$ es global y asintóticamente estable en $\Omega$.

Demostración. Sea $L(t)=V(t)$, donde $V(t)$ es la solución del sistema (3). Así $L(t)$ es una función definida positiva y por lo tanto puede ser candidata a ser función de Lyapunov. Este tipo de definición de la función está inspirada en lo hecho en trabajos como $[6,18,22,43,50,61,60]$. La derivada de $L$ a lo largo de las trayectorias de (3) es,

$$
\begin{aligned}
\frac{d L}{d t}=\dot{V} & =\frac{N \delta \beta V T}{k+V}-c V \\
& =c V\left(\frac{N \delta \beta T}{c(k+V)}-1\right) \\
& =c V\left(\frac{k}{k+V} \frac{N \delta \beta \sigma}{c k \mu} \frac{\mu}{\sigma} T-1\right) .
\end{aligned}
$$

Teniendo en cuenta la definición dada para $R_{0}$ en (4) y denotando $\bar{T}_{0}=\frac{\sigma}{\mu}$ al valor en equilibrio de las células $T$ en ausencia de infección, se puede escribir:

$$
\frac{d L}{d t}=c V\left(\frac{k}{k+V} R_{0} \frac{T}{\bar{T}_{0}}-1\right) \leq c V\left(R_{0} \frac{T}{\bar{T}_{0}}-1\right) \leq c V\left(R_{0}-1\right) .
$$

Puesto que $\frac{k}{k+V} \leq 1$ para la primera desigualdad y teniendo en cuenta que $T \leq$ $\bar{T}_{0}$ para la segunda. Así, se tiene que cuando $R_{0} \leq 1$ entonces $\frac{d L}{d t} \leq 0$. De acuerdo con lo anterior, $\frac{d L}{d t}=0$ si y sólo si $V=0$ ó $R_{0}=1$. En cualquier caso, por la Proposición 2.2, el máximo conjunto de invarianza en $\left\{(T, V) \in \Omega: \frac{d L}{d t}=0\right\}$ es $\left\{E_{0}\right\}$ y así, el principio de invarianza de LaSalle $[6,18,27,33,50,61]$ implica que todas las soluciones convergen a $E_{0}$, por lo tanto, el equilibrio trivial es global y asintóticamente estable.

Proposición 2.5 El equilibrio no trivial $E_{1}$ del sistema (3) es local y asintóticamente estable si y sólo si $R_{0}>1$.

Demostración. Al evaluar la matriz jacobiana (5) en el equilibrio $E_{1}$ y simplificar, se obtiene,

$$
J_{1}=\left[\begin{array}{cc}
-\frac{\sigma N \delta(\beta+\mu)}{\sigma N \delta+c k} & -\frac{(\beta+\mu) c^{2} k}{\beta N \delta(\sigma N \delta+c k)} \\
\frac{(\beta \sigma N \delta-c k \mu) N \delta}{\sigma N \delta+c k} & -\frac{(\beta \sigma N \delta-c k \mu) c}{\beta(\sigma N \delta+c k)}
\end{array}\right],
$$


de donde la traza $\tau$ y el determinante $\Delta$ de la matriz están dados por

$$
\tau=-\frac{\beta \sigma N \delta(\beta+\mu)+c^{2} k \mu\left(R_{0}-1\right)}{\beta(\sigma N \delta+c k)} \quad \text { y } \quad \Delta=\frac{(\beta+\mu) c^{2} k \mu\left(R_{0}-1\right)}{\beta(\sigma N \delta+c k)} .
$$

Puede verse que $R_{0}>1$ es condición suficiente para que $\tau<0$ y es condición necesaria para $\Delta>0$, y en consecuencia para que $E_{1}$ sea local y asintóticamente estable, según el criterio de traza-determinante.

Nótese que después de algunas manipulaciones algebraicas, se puede mostrar que $\tau>0$ implica que $R_{0}<1-\frac{\beta \sigma \delta N(\beta+\mu)}{c^{2} k \mu}$, de donde $R_{0}<1$ y por lo tanto $\Delta<0$. En consecuencia, $E_{1}$ es inestable por el criterio de traza-determinante, y según la Proposición 2.3, $E_{0}$ es localmente asintóticamente estable. Por lo tanto $R_{0}>1$ es condición necesaria y suficiente para garantizar la estabilidad local y asintótica de $E_{1}$.

Es importante observar a partir de las tres proposiciones de estabilidad anteriores, que para $R_{0} \leq 1$ la infección no se establece en el organismo. Mientras que cuando $R_{0}>1$ la infección prospera. Desde el punto de vista matemático, puede considerarse que el umbral $R_{0}$ es útil para establecer estrategias orientadas a controlar la infección. Sin embargo, es necesario aclarar que ese control de la infección es teórico y una sencilla explicación desde el punto de vista inmunológico, puede ser que $R_{0}<1$ describa escenarios en que la carga viral se encuentra en niveles no detectables.

\subsection{Umbral de control mediante la reducción de la tasa máxima de infección $\beta$}

Retomando el número básico de reproducción y considerándolo una función de los parámetros $\beta$ y $N$, que corresponden a la tasa máxima de infección y a la tasa de producción viral, respectivamente, se puede determinar un valor umbral $\beta_{m}$, en función de $N$, tal que si $\beta \leq \beta_{m}$, entonces $R_{0}(\beta, N) \leq 1$, y si $\beta>\beta_{m}$, entonces $R_{0}(\beta, N)>1$. En efecto,

$$
\beta_{m}(N)=\frac{c k \mu}{\sigma \delta N}
$$

donde $\beta_{m}$ está siendo definido en función de $N$. La gráfica de esta función divide el primer cuadrante del plano de parámetros $\beta N$ en dos regiones que corresponden a $R_{0}<1$ cuando la pareja $(\beta, N)$ se encuentra por debajo de la curva y a $R_{0}>1$ cuando la pareja $(\beta, N)$ se encuentra por encima de la curva. En la Figura 2 se ilustra este resultado con los parámetros de la Tabla 1, en la que se puede apreciar que si lo que se quiere son escenarios libre de infección, 
entonces para valores muy grandes de $N$, el valor de $\beta$ debe ser pequeño y viceversa.

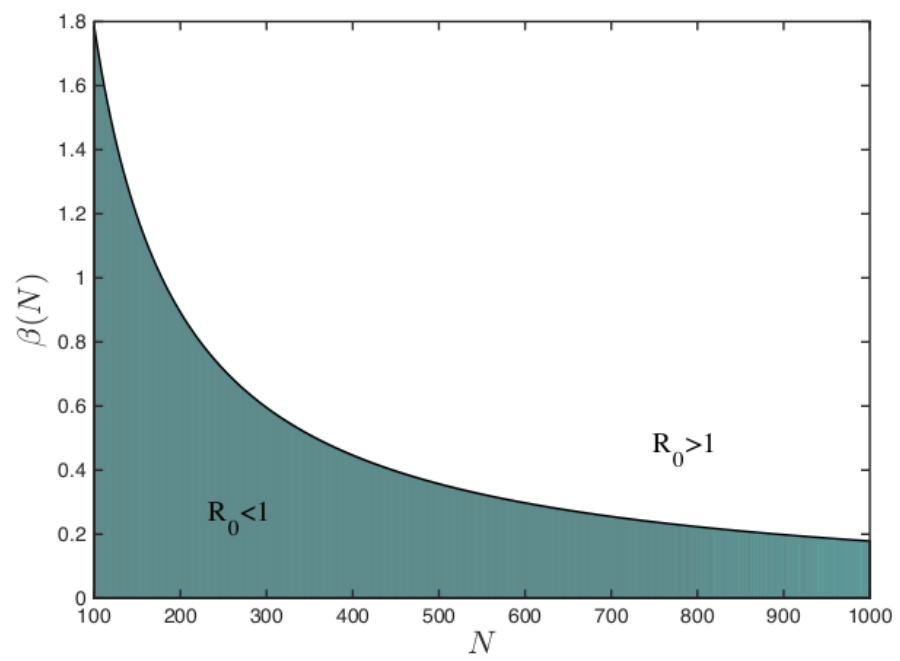

Figura 2: Se muestra la curva $\beta_{m}(N)=\frac{c k \mu}{\sigma \delta N}$ la cual divide el primer cuadrante en dos regiones que corresponden a $R_{0}<1$ cuando la pareja $(\beta, N)$ se encuentra por debajo de la curva y a $R_{0}>1$ cuando la pareja $(\beta, N)$ se encuentra por encima de la curva. Se usaron los parámetros de la Tabla $1, \beta \in[0,1]$ y $N \in[100,1000]$.

\subsection{Simulación numérica del modelo}

La simulación del sistema (3) que se muestra en la Figura 3 fue hecha considerando un tiempo final de simulación $\tau=300$ días y usando los parámetros de la Tabla 1, con los que se obtiene el valor umbral $\beta_{m}=0.0714$. Con el único fin de ilustrar, al parámetro $\beta$ se le asignaron cuatro valores arbitrarios que satisfacen la condición $\beta>\beta_{m}$, los cuales se muestran en la primera columna de la Tabla 2, al igual que los correspondientes valores de $R_{0}$ en la segunda columna. El tipo de línea respectivo a cada valor de $\beta$ que se ha usado en la figura es: línea continua, punteada, raya-raya y raya-punto.

Es importante observar que la magnitud del parámetro $\beta$ influye considerablemente en la altura del pico de infección inicial. En particular, para el valor más alto de $\beta$ usado en esta simulación ( $\beta=0.160357)$, e ilustrado con la curva raya-punto, se obtienen los niveles más bajos de células $T$ y los más altos de la carga viral $V$. 
Las cuatro soluciones que se muestran corresponden a escenarios con $R_{0}>1$; por lo tanto el comportamiento del sistema es como se establece en la Proposición 2.5; con los valores finales de las variables de estado en la tercera y cuarta columnas de la Tabla 2.

De manera semejante, en la Figura 4 se muestran las soluciones del sistema (3) con cuatro valores ad hoc de la tasa de saturación media $k$, los cuales se muestran en la primera columna de la Tabla 2 al igual que los correspondientes valores de $R_{0}$ en la segunda columna. El tipo de línea respectivo a cada valor de $k$ que se ha usado en la figura es: línea continua, punteada, raya-raya y raya-punto.
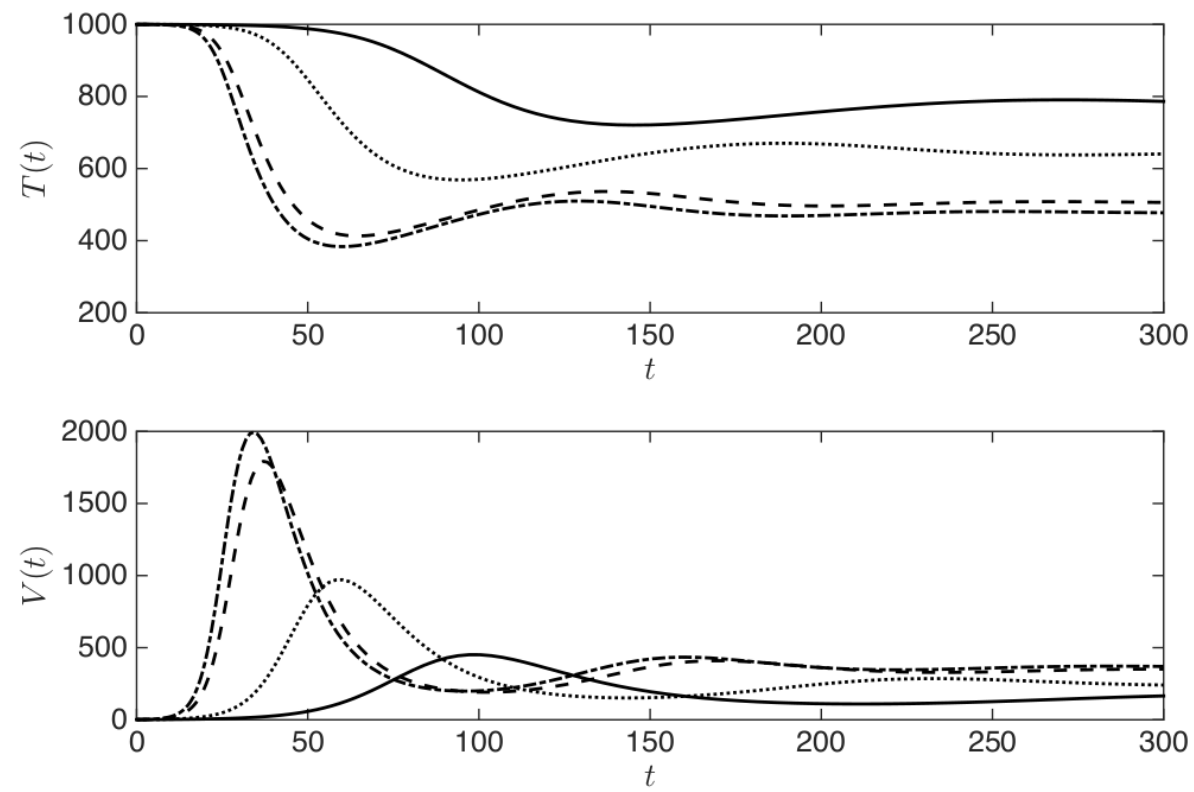

Figura 3: Soluciones numéricas del sistema (3) con $k=5000, \tau=300$ días, con cuatro valores diferentes para $\beta=(0.095,0.1162,0.1511,0.1604)$ y los demás parámetros mostrados en la Tabla 1. Los correspondientes valores del número básico de reproducción son $R_{0}=$ $(1.332407,1.626858,2.115578,2.244995)$. El tipo de línea respectivo a cada valor de $\beta$ que se ha usado en la figura es: línea continua, punteada, raya-raya y raya-punto.

Puede notarse que incrementar $k$ tiene el efecto de reducir la magnitud del $R_{0}$, lo que implica que tasas de saturación altas conllevan a menores niveles de viremia y un menor impacto en la población de células $T$. En ese sentido, 
conocer de manera mas precisa la respuesta del virus frente a su propia densidad sería importante a la hora de estimar el comportamiento futuro de la infección por VIH.

Al igual que en el caso anterior, las cuatro soluciones que se muestran corresponden a escenarios con $R_{0}>1$; por lo tanto, el comportamiento del sistema es como se establece en la Proposición 2.5; los valores finales de las variables de estado obtenidos con la simulación se muestran en la tercera y cuarta columna de la Tabla 2.
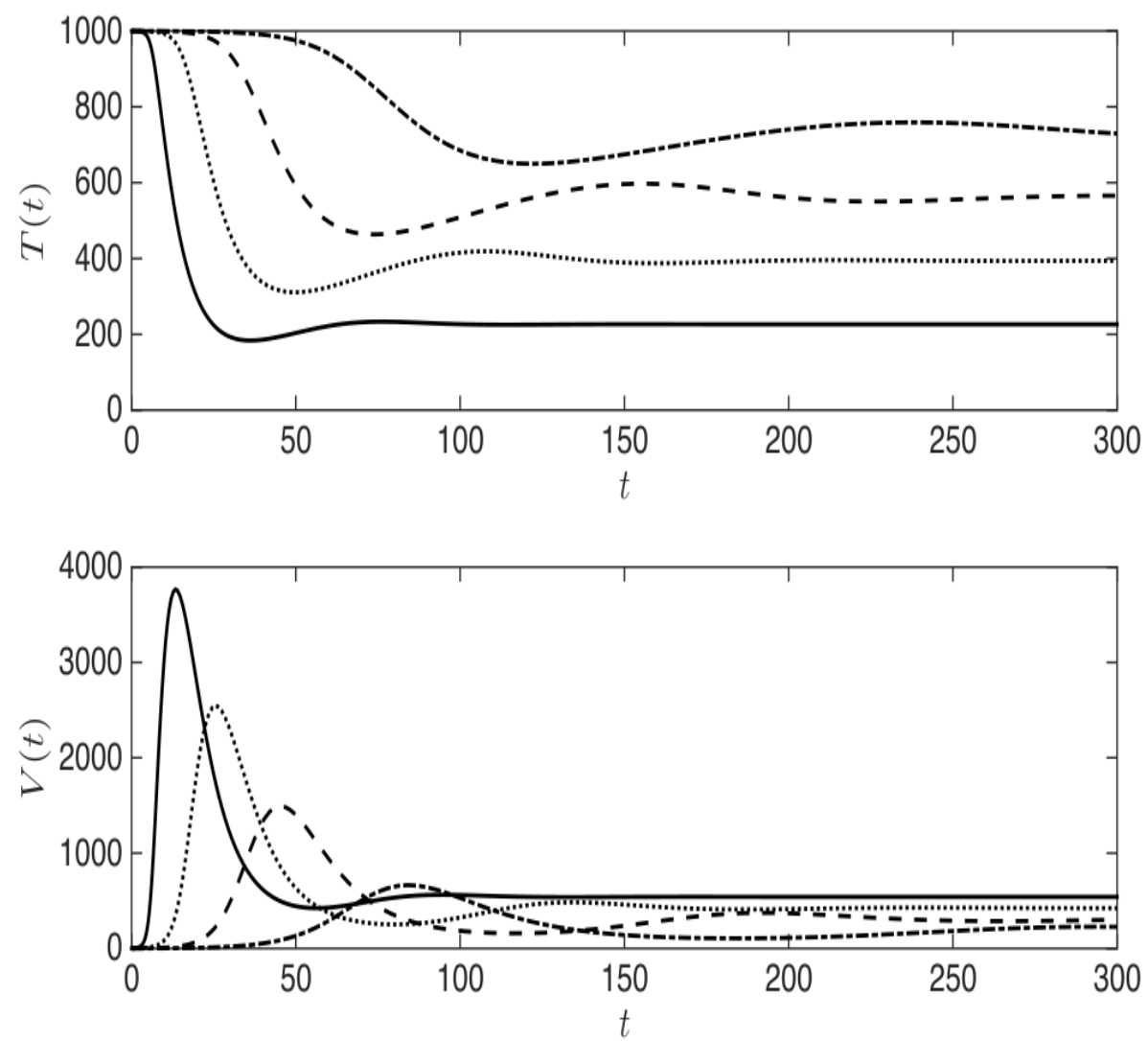

Figura 4: Soluciones numéricas del sistema (3) con $\beta=0.160357, \tau=300$ días, con cuatro valores diferentes para $k=(2000,4000,6000,8000)$ y los demás parámetros mostrados en la Tabla 1 . Los correspondientes valores del número básico de reproducción son $R_{0}=$ $(5.612486,2.806243,1.870829,1.403122)$. El tipo de línea respectivo a cada valor de $k$ que se ha usado en la figura es: línea continua, punteada, raya-raya y raya-punto. 
Tabla 2: En la mitad superior de la tabla se observan los valores de $\beta$ usados en la simulación de las Figuras 3 y 4, respectivamente. Los demás parámetros corresponden a los mostrados en la Tabla 1. En cada caso se muestra el correspondiente valor de $R_{0}$ y los valores finales de las variables de estado $T$ y $V$ obtenidos con la simulación.

\begin{tabular}{l|lll}
\hline \hline$\beta$ & $R_{0}$ & $T(\tau) \mathrm{mm}^{-3}$ & $V(\tau) \mathrm{mm}^{-3}$ \\
\hline 0.095172 & 1.332407 & 786.316894 & 165.328828 \\
0.116204 & 1.626858 & 640.561733 & 240.924288 \\
0.151113 & 2.115578 & 506.027076 & 351.786327 \\
0.160357 & 2.244995 & 477.427309 & 369.787806 \\
\hline \hline$k$ & $R_{0}$ & $T(\tau) \mathrm{mm}^{-3}$ & $V(\tau) \mathrm{mm}^{-3}$ \\
\hline 2000 & 5.612486 & 226.415627 & 541.508937 \\
4000 & 2.806243 & 394.123557 & 423.104614 \\
6000 & 1.870829 & 565.740294 & 301.509166 \\
8000 & 1.403122 & 729.542192 & 227.097589 \\
\hline \hline
\end{tabular}

\section{Tratamiento de la infección por VIH mediante antirretrovirales}

Frente a la infección por VIH, los sistemas de salud proporcionan medicamentos para su tratamiento, los cuales buscan mitigar el impacto que la enfermedad tiene sobre los pacientes y mejorar sus condiciones y expectativa de vida. Establecer el tipo de tratamiento y la intensidad con que este se debe aplicar es responsabilidad del médico tratante y está fundamentada en características específicas del virus y de las condiciones inmunológicas del paciente entre otras [2].

El tratamiento antrirretroviral (TAR) de alta intensidad, consiste en una combinación de medicamentos. El principal enfoque de los tratamientos desarrollados es inhibir el proceso de replicación del virus, que es realizado a través de sus tres enzimas principales: la transcriptasa inversa, la integrasa y la proteasa. Para ello se han creado los tratamientos basados en inhibidores nucleótidos y no nucleótidos de la transcriptasa inversa (ITI), los inhibidores de la integrasa (II), los inhibidores de la proteasa (IP) y los inhibidores de fusión (IF). Una descripción amplia de su funcionamiento se puede encontrar en [3, 2, 45].

Estos tratamientos han probado ser extremadamente efectivos: los pacientes mantienen bajas cargas virales y tienen el sistema inmune restablecido a niveles de baja vulnerabilidad frente a infecciones letales. Sin embargo, el TAR de alta intensidad se caracteriza por tener considerables efectos secundarios sobre los 
pacientes; de manera general se puede destacar que se presentan crisis nerviosas, anemia, dolor, debilidad y redistribución de la grasa. Efectos secundarios de mayor gravedad debidos a la alta toxicidad del tratamiento son la adquisición de resistencia frente a la insulina, patologías cardiovasculares, hepatitis o miopatías, entre otras, reportados con frecuencia en la literatura [1, 7, 11, 14, 16, 24, 38, 39].

En particular los ITI bloquean la recodificación del ARN viral en ADN para que no sea reconocible por el genoma de la célula, de modo que el ARN viral es eventualmente degradado. El uso de ITI efectivos implica que la célula $T$ objetivo no resulta infectada por el virus. Por otro lado, los IP actúan en células que ya han sido infectadas y se encuentran replicando activamente el virus. Los IP evitan que se dé el correcto empaquetamiento del material constitutivo del virus, dando origen a partículas virales defectuosas.

De acuerdo con los resultados de la sección anterior y con la descripción dada de los ITI y los IP, es posible controlar la infección mediante la aplicación de tratamiento, manipulando los términos que describen la infección de células $\mathrm{T}$ y la producción de nuevas partículas virales, con el fin de lograr que $R_{0}<1$, lo que teóricamente garantizaría niveles muy bajos (no detectables) de infección. En esta sección se formulará un modelo similar al sistema (3) pero que considera la aplicación de ITI y de IP en la dinámica de infección.

\subsection{Formulación del sistema con tratamiento antirretroviral}

En este trabajo se define efectividad del tratamiento como una medida en el intervalo $[0,1]$ de la capacidad que tienen los medicamentos administrados de reducir la carga viral de un paciente infectado. Sean $u_{1}=u_{1}(t)$ y $u_{2}=u_{2}(t)$ las efectividades correspondientes a los ITI y los IP, respectivamente en un tiempo $t$. Se asume que $u_{1,2}(t) \equiv 0$ indica que no se aplica el tratamiento o que su efectividad es nula y que $u_{1,2}(t) \equiv 1$ significa que el tratamiento es $100 \%$ efectivo. De este modo, el número promedio de células $T$ que se infecta en un tiempo $t$, descrito por $\frac{\beta V T}{k+V}$ en la formulación del modelo (3), se reexpresa como $\left(1-u_{1}\right) \frac{\beta T V}{k+V}$, término que establece el número promedio de células $T$ que resultan infectadas al fallar los ITI; en efecto, los ITI son medicamentos que evitan que la transcriptasa inversa que liberan las partículas virales en el citoplasma celular, pueda retrotranscribir el ARN viral en cadenas de $\mathrm{ADN}$ reconocibles por el núcleo de la célula y de este modo, no es posible que se dé el proceso de replicación viral, de hecho, cuando los ITI son efectivos la célula no llega a ser formalmente infectada por el virus. 
De este modo la ecuación que describe la dinámica de las células $T$ queda dada por,

$$
\dot{T}=\sigma-\left(1-u_{1}\right) \frac{\beta T V}{k+V}-\mu T .
$$

Por otro lado, el número de partículas virales producidas depende de la cantidad de células $T$ infectadas que mueren por causas relacionadas con el virus, proceso que ocurre continuamente en el organismo de una persona infectada, y por lo cual no se considera de manera explícita una categoría para las células $T$ infectadas. Como $\delta$ es la tasa de muerte de células $T$ infectadas que mueren por causas relacionadas con el virus (p.ej. lisis celular), entonces se puede decir que en cada tiempo $t$ muere un promedio de $\delta\left(1-u_{1}\right) \frac{\beta T V}{k+V}$ células $T$ infectadas. Adicionalmente, con $N$ la producción viral de cada célula infectada, entonces $N \delta\left(1-u_{1}\right) \frac{\beta T V}{k+V}$ es el número promedio de viriones producidos en un tiempo $t$, considerando solo la aplicación de ITI. Por otro lado, la administración de los IP debe tener el efecto de reducir ese número de viriones producidos, de manera que cuando los IP fallan, $N \delta\left(1-u_{1}\right)\left(1-u_{2}\right) \frac{\beta T V}{k+V}$ determina el número promedio de viriones producidos en un tiempo $t$, expresión que considera la administración de ITI y de IP. Con las consideraciones hechas, la ecuación que describe la variación de las partículas virales queda de la forma:

$$
\dot{V}=N \delta\left(1-u_{1}\right)\left(1-u_{2}\right) \frac{\beta T V}{k+V}-c V \text {. }
$$

Teniendo en cuenta que los IP evitan que las proteasas cumplan con su función en el proceso de ensamble de las partículas virales; es decir, que los IP evitan que esas partículas virales producidas sean infecciosas, se hace conveniente considerar una nueva variable de estado $W=W(t)$ para denotar el número promedio de partículas virales defectuosas producidas en un tiempo $t$, la cual crece a un promedio $N \delta u_{2}\left(1-u_{1}\right) \frac{\beta T V}{k+V}$ y decae según la tasa de eliminación de virus $c$. De este modo, la ecuación que describe la dinámica de las partículas virales defectuosas o no infecciosas es:

$$
\dot{W}=N \delta u_{2}\left(1-u_{1}\right) \frac{\beta T V}{k+V}-c W .
$$

Note que el factor $u_{2}$ que aparece en la ecuación anterior, refleja que la magnitud promedio $W$ es resultado de la intervención efectiva de los IP en el proceso de ensamble del virión; en efecto, el término positivo en la ecuación (7) sumado con el término positivo de (8) dan cuenta del total de partículas virales producidas entre defectuosas $W$ e infecciosas $V$. 
De este modo, las ecuaciones (6), (7) y (8) conforman el sistema de ecuaciones diferenciales que describe la dinámica con tratamiento antirretroviral:

$$
\left\{\begin{array}{l}
\dot{T}=\sigma-\left(1-u_{1}\right) \frac{\beta T V}{k+V}-\mu T \\
\dot{V}=N \delta\left(1-u_{1}\right)\left(1-u_{2}\right) \frac{\beta T V}{k+V}-c V \\
\dot{W}=N \delta u_{2}\left(1-u_{1}\right) \frac{\beta T V}{k+V}-c W .
\end{array}\right.
$$

El sistema anterior está sujeto a condiciones iniciales $T(0)=T_{0}, V(0)=V_{0}$ y $W(0)=W_{0}$ todas no negativas y los parámetros coinciden con la descripción que se hace en la Tabla 1. Es importante mencionar que el sistema (9) es no autónomo, anteriormente se dijo que $u_{1}=u_{1}(t)$ y $u_{2}=u_{2}(t)$ son las efectividades correspondientes a los ITI y los IP, respectivamente en un tiempo $t$, y por eso no se lleva a cabo análisis de estabilidad en términos de umbrales.

Tres escenarios interesantes surgen según la efectividad de los antirretrovirales, a saber: cuando la efectividad es nula $u_{1,2}(t) \equiv 0$, cuando la efectividad es total $u_{1,2}(t) \equiv 1$ y cuando la efectividad es imperfecta $0<u_{1,2}(t)<1$.

Antirretrovirales de efectividad nula. Note que si $u_{1,2}(t) \equiv 0$, entonces el modelo (9) se reduce a la expresión

$$
\left\{\begin{aligned}
\dot{T} & =\sigma-\frac{\beta T V}{k+V}-\mu T \\
\dot{V} & =\frac{N \delta \beta T V}{k+V}-c V \\
\dot{W} & =-c W
\end{aligned}\right.
$$

Nótese que la tercera ecuación está desacoplada en el sistema (10), y describe el decaimiento exponencial de $W$ cuando $t \rightarrow \infty$. Sin embargo, frente a la ausencia de tratamiento (o tratamiento de efectividad nula), el sistema no permite la creación de partículas virales defectuosas como resultado de los IP, situación que se evidencia en el caso particular ilustrado en la Figura 5, donde la condición inicial se ha considerado $W(0)=0$. Las otras dos ecuaciones corresponden a las estudiadas en el modelo (3), cuyo comportamiento para $R_{0}>1$ ya fue descrito previamente en la Proposición 2.5.

Antirretrovirales de efectividad plena. Cuando $u_{1,2}(t) \equiv 1$, se tendrá el sistema de ecuaciones diferenciales,

$$
\left\{\begin{array}{c}
\dot{T}=\sigma-\mu T \\
\dot{V}=-c V \\
\dot{W}=-c W
\end{array}\right.
$$



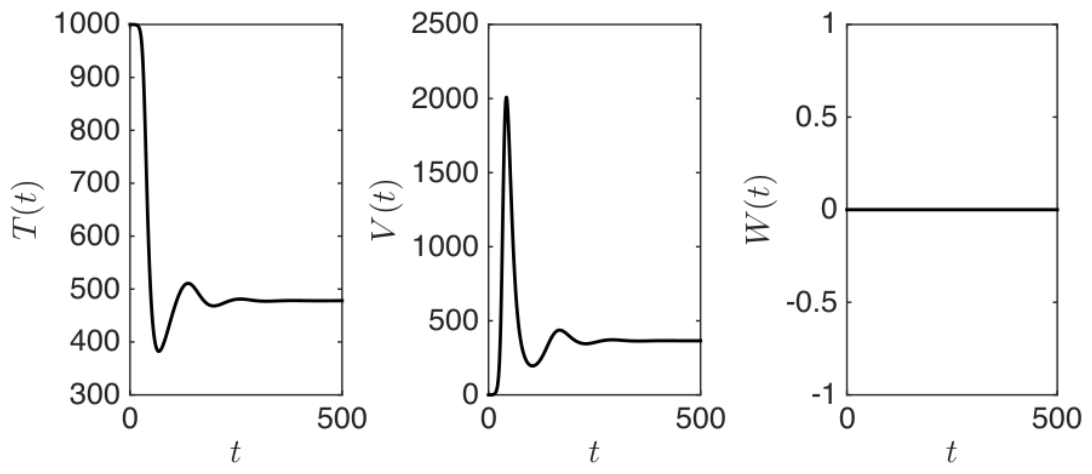

Figura 5: Simulación numérica del modelo con tratamiento antirretroviral con efectividad nula descrito en el sistema (10). La simulación numérica se hizo con los parámetros descritos en la Tabla 1, con los que se obtiene $R_{0}>1$.
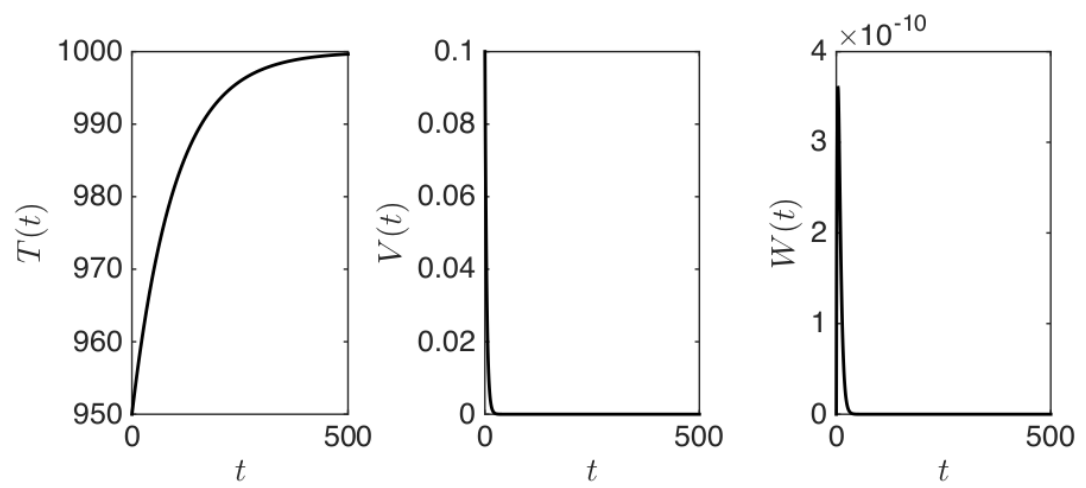

Figura 6: Simulación numérica del modelo con tratamiento antirretroviral con efectividad plena descrito en el sistema (11). La simulación se hizo con los parámetros descritos en la Tabla 1.

El sistema (11) tiende al equilibrio $(\sigma / \mu, 0,0)$ cuando $t \rightarrow \infty$. En efecto, la ecuación para $T$ es lineal y alcanza el nivel de equilibrio $\sigma / \mu$ cuando $t \rightarrow \infty$. Por otro lado, las ecuaciones para $V$ y $W$ describen decaimiento exponencial y sus soluciones tienden a cero cuando $t \rightarrow \infty$, como se ilustra en la Figura 6 . Este es un escenario ideal en que el tratamiento teóricamente elimina la infección, sin embargo, como en la práctica médica no se ha logrado eliminar la infección, es posible que este resultado en el contexto fisiológico pueda interpretarse como que el virus es reducido a niveles no detectables en el organismo del paciente. 


\subsection{Antirretrovirales de efectividad imperfecta}

Este escenario considera que las efectividades del tratamiento antirretroviral se encuentran en el rango $(0,1)$. En ese sentido, se pretende encontrar expresiones óptimas para las efectividades $u_{1}^{*}=u_{1}^{*}(t)$ y $u_{2}^{*}=u_{2}^{*}(t)$, que sirvan como estrategia de tratamiento que garanticen una reducción del número promedio de partículas virales (carga viral) $V$ al mismo tiempo que se minimizan los costos directos y/o indirectos de la administración de ese tratamiento óptimo.

Sean $A$ y $B$ pesos constantes que ponderan la aplicación de los tratamientos, y se define a $J$ como la funcional que acumula los costos de aplicar los controles, la cual se asume cuadrática por simplicidad y con base en lo hecho en trabajos como $[11,25,41,49,57,58]$ y viene dada por,

$$
J\left(u_{1}, u_{2}\right)=\int_{0}^{\tau}\left(V(t)+\frac{A}{2} u_{1}^{2}(t)+\frac{B}{2} u_{2}^{2}(t)\right) d t .
$$

Es claro que la variable de estado $V$ también podría tener un peso o factor asociado que represente la importancia que se le da a su disminución, pero en este trabajo se propone establecer solo el impacto sobre los controles que tiene la variación de los ponderadores $A$ y $B$. Con el fin de que la suma descrita en el integrando tenga sentido, debe considerarse que los pesos $A$ y $B$ no solo están relacionados con los costos directos y/o indirectos del tratamiento, sino que también se definen de forma que coincidan las unidades en que se definen los términos que se suman.

La funcional $J$ está sujeta al sistema (9); de este modo, el objetivo es determinar un par de funciones óptimas $\left(u_{1}^{*}, u_{2}^{*}\right) \in \Gamma$ tales que $J\left(u_{1}^{*}, u_{2}^{*}\right) \leq J\left(u_{1}, u_{2}\right)$, para todo par $\left(u_{1}, u_{2}\right) \in \Gamma$, y donde $\Gamma$ es el conjunto de controles admisibles determinado por,

$$
\Gamma=\left\{u_{1}, u_{2} \in L^{2}([0, \tau]): 0 \leq u_{1} \leq 1,0 \leq u_{2} \leq 1\right\} .
$$

\subsubsection{Aplicación del Principio de Máximo de Pontryagin}

Para determinar el par óptimo $\left(u_{1}^{*}, u_{2}^{*}\right)$ se acude el Principio del Máximo de Pontryagin, y para ello se define la que se llama función hamiltoniana, como se describe en $[15,35]$ :

$$
\begin{aligned}
H=V & +\frac{A}{2} u_{1}^{2}+\frac{B}{2} u_{2}^{2}+L_{1}\left(\sigma-\beta\left(1-u_{1}\right) T \frac{V}{1+k V}-\mu T\right) \\
& +L_{2}\left(N \delta \beta\left(1-u_{1}\right)\left(1-u_{2}\right) T \frac{V}{1+k V}-c V\right) \\
& +L_{3}\left(N \delta \beta u_{2}\left(1-u_{1}\right) T \frac{V}{1+k V}-d W\right) .
\end{aligned}
$$


Sean $z_{i}$, para $i=1,2,3,4$, cantidades de penalización no negativas usadas para garantizar que $0 \leq u_{1} \leq 1$ y que $0 \leq u_{2} \leq 1$ y deben satisfacer,

$$
z_{1}\left(1-u_{1}\right)=0, \quad z_{2} u_{1}=0, \quad z_{3}\left(1-u_{2}\right)=0 \quad \text { y } \quad z_{4} u_{2}=0 .
$$

Según el principio del máximo de Pontryagin, se establece un sistema adjunto cuyas ecuaciones están dadas por $\dot{L}_{1}=-\frac{\partial H}{\partial T}, \dot{L}_{2}=-\frac{\partial H}{\partial V}$ y $\dot{L}_{3}=-\frac{\partial H}{\partial W}$ con lo que se obtiene,

$$
\left\{\begin{aligned}
\dot{L}_{1}= & L_{1}\left(\frac{\beta\left(1-u_{1}\right) V}{k+V}+\mu\right)-L_{2} \frac{N \delta \beta\left(1-u_{1}\right)\left(1-u_{2}\right) V}{k+V}-L_{3} \frac{N \delta \beta\left(1-u_{1}\right) u_{2} V}{k+V} \\
\dot{L}_{2}= & -1-L_{1}\left(-\frac{\beta\left(1-u_{1}\right) T}{k+V}+\frac{\beta\left(1-u_{1}\right) T V}{(k+V)^{2}}\right)-L_{2}\left(\frac{N \delta \beta\left(1-u_{1}\right)\left(1-u_{2}\right) T}{k+V}\right. \\
& \left.-\frac{N \delta \beta\left(1-u_{1}\right)\left(1-u_{2}\right) T V}{(k+V)^{2}}-c\right)-L_{3}\left(\frac{N \delta \beta\left(1-u_{1}\right) u_{2} T}{(k+V)}-\frac{N \delta \beta\left(1-u_{1}\right) u_{2} T V}{(k+V)^{2}}\right) \\
\dot{L}_{3}= & L_{3} c .
\end{aligned}\right.
$$

Con condiciones finales $L_{i}(\tau)=0$, para $i=1,2,3$. Las funciones óptimas de tratamiento se obtienen de resolver el sistema formado por las ecuaciones $\frac{\partial H}{\partial u_{1}}=0$ y $\frac{\partial H}{\partial u_{2}}=0$ y usar las condiciones de penalización, explícitamente:

$$
u_{1}^{*}(t)=\max \left(0, \min \left(\tilde{u}_{1}, 1\right)\right) \quad u_{2}^{*}(t)=\max \left(0, \min \left(\tilde{u}_{2}, 1\right)\right),
$$

donde,

$\tilde{u}_{1}=\frac{\left(L_{2}^{2} N^{2} T V \beta \delta^{2}-2 L_{2} L_{3} N^{2} T V \beta \delta^{2}+L_{3}^{2} N^{2} T V \beta \delta^{2}-B L_{2} N V \delta-B L_{2} N \delta k+B L_{1} V+B L_{1} k\right) T V \beta}{L_{2}^{2} N^{2} T^{2} V^{2} \beta^{2} \delta^{2}-2 L_{2} L_{3} N^{2} T^{2} V^{2} \beta^{2} \delta^{2}+L_{3}^{2} N^{2} T^{2} V^{2} \beta^{2} \delta^{2}-A B V^{2}-2 A B V k-A B k^{2}}$
$\tilde{u}_{2}=\frac{N T V \beta \delta\left(L_{2}-L_{3}\right)\left(-L_{2} N T V \beta \delta+L_{1} T V \beta+A V+A k\right)}{-L_{2}^{2} N^{2} T^{2} V^{2} \beta^{2} \delta^{2}+2 L_{2} L_{3} N^{2} T^{2} V^{2} \beta^{2} \delta^{2}-L_{3}^{2} N^{2} T^{2} V^{2} \beta^{2} \delta^{2}+A B V^{2}+2 A B V k+A B k^{2}}$. De
este modo, con (9), (12) y (13) se conforma un problema de contorno de dos puntos dado por,

$$
\left\{\begin{aligned}
\dot{T} & =\sigma-\left(1-u_{1}^{*}\right) \frac{\beta T V}{k+V}-\mu T \\
\dot{V} & =N \delta\left(1-u_{1}^{*}\right)\left(1-u_{2}^{*}\right) \frac{\beta T V}{k+V}-c V \\
\dot{W} & =N \delta u_{2}^{*}\left(1-u_{1}^{*}\right) \frac{\beta T V}{k+V}-c W \\
\dot{L}_{1} & =L_{1}\left(\frac{\beta\left(1-u_{1}^{*}\right) V}{k+V}+\mu\right)-L_{2} \frac{N \delta \beta\left(1-u_{1}^{*}\right)\left(1-u_{2}^{*}\right) V}{k+V}-L_{3} \frac{N \delta \beta\left(1-u_{1}^{*}\right) u_{2}^{*} V}{k+V} \\
\dot{L}_{2} & =-1-L_{1}\left(-\frac{\beta\left(1-u_{1}^{*}\right) T}{k+V}+\frac{\beta\left(1-u_{1}^{*}\right) T V}{(k+V)^{2}}\right)-L_{2}\left(\frac{N \delta \beta\left(1-u_{1}^{*}\right)\left(1-u_{2}^{*}\right) T}{k+V}\right. \\
& \left.-\frac{N \delta \beta\left(1-u_{1}^{*}\right)\left(1-u_{2}^{*}\right) T V}{(k+V)^{2}}-c\right)-L_{3}\left(\frac{N \delta \beta\left(1-u_{1}^{*}\right) u_{2}^{*} T}{(k+V)}-\frac{N \delta \beta\left(1-u_{1}^{*}\right) u_{2}^{*} T V}{(k+V)^{2}}\right) \\
\dot{L}_{3} & =L_{3} c .
\end{aligned}\right.
$$

Sujeto a las condiciones iniciales $T(0)=T_{0}, V(0)=V_{0}$ y $W(0)=W_{0}$ y a las condiciones finales $L_{i}(\tau)=0$, para $i=1,2,3$. 
Las soluciones óptimas de este sistema, que se obtienen con $u_{1}^{*}(t)$ y $u_{2}^{*}(t)$ como están definidos en (13), son las que minimizan el número de partículas virales $V$ y los costos directos e indirectos de aplicar los controles, tal y como se estableció en la formulación del funcional $J$. En este trabajo no se hará un seguimiento explícito al valor de $J$ en cada escenario, reconociendo que cada solución $u_{1,2}^{*}(t)$ que se ilustra en las simulaciones, será la que minimiza $J$ para ese escenario. En las simulaciones se ilustrará la forma como las funciones de control óptimas $u_{1,2}^{*}(t)$ responden a las variaciones de $A$ y de $B$, que son los ponderadores asociados a cada una de ellas, en particular, por la dependencia que puede observarse en (13).
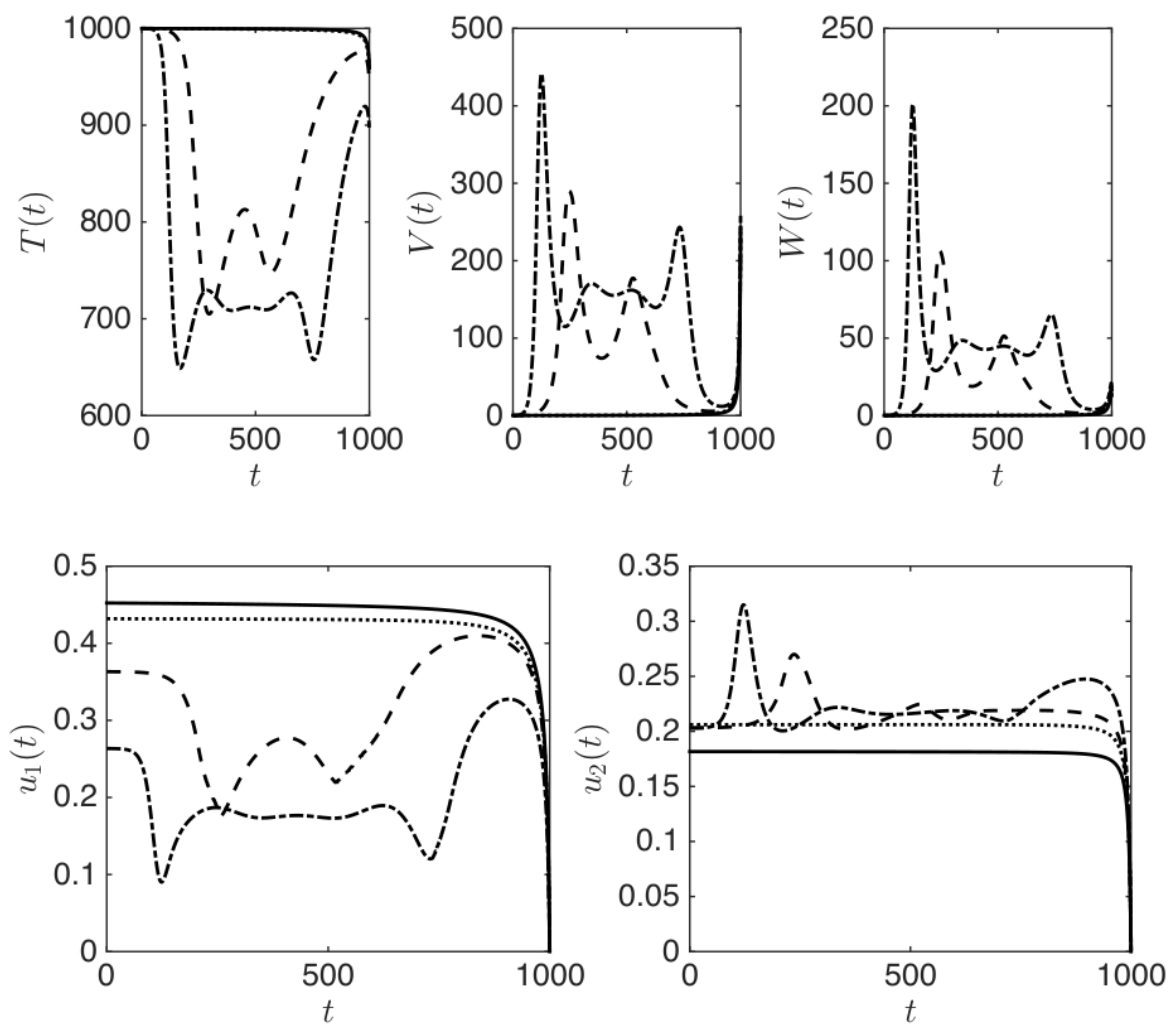

Figura 7: Simulación numérica del problema de contorno (14) con efectividad imperfecta, es decir con $u_{i}^{*} \in(0,1)$, para $i=1,2$, se hizo con los parámetros descritos en la Tabla $1, B=3000$ y $A=(1800,2000,2100,2500)$. Las curvas se representan con línea continua, punteada, raya-raya y raya-punto, respectivamente. 


\subsubsection{Simulación con antirretrovirales de efectividad imperfecta}

Dadas las características del problema de contorno (14), no es posible hallar soluciones analíticas, y se ha optado por estudiar las soluciones numéricamente. Para ello se elabora un algoritmo que efectúa integración hacia adelante únicamente de las ecuaciones diferenciales correspondientes a las variables de estado $T, V$ y $W$, a partir de las correspondientes condiciones iniciales. Una vez se tiene esta solución se usa para integrar hacia atrás solamente las ecuaciones diferenciales correspondientes a las variables adjuntas $L_{i}$, para $i=1,2,3$, a partir de las condiciones finales; método que es descrito detalladamente en [35] y denominado del $\hat{A} «$ barrido hacia adelante y hacia atrás $\hat{A} »$ y que no requiere conocer las condiciones iniciales de las variables adjuntas, ni el valor final de las variables de estado, como ocurre con otros métodos; información detallada sobre la convergencia y estabilidad de este método puede ser consultada en [20]. Múltiples iteraciones de este proceso se hacen con el fin de actualizar las funciones de control hasta que se satisface una tolerancia al error $\epsilon$. En este trabajo se usa como norma la expresión, $\sum_{i=1}^{6}\left|x_{i}-x_{i}^{a}\right|<\epsilon$, donde $x_{i}$ representa una aproximación $\hat{\mathrm{A}}$ «actual $\hat{\mathrm{A}}$ » de cada variable (de estado y adjunta) y $x_{i}^{a}$ denota la aproximación $\hat{\mathrm{A}}$ «anterior $\hat{A} »$ de la variable y se ha usado $\epsilon=10^{-5}$.

La simulación numérica mostrada en la Figura 7 se hizo con los parámetros descritos en la Tabla $1, B=3000$ y muestra las soluciones del sistema (14) para cuando $A=(1800,2000,2100,2500)$. Las curvas se representan con línea continua, punteada, raya-raya y raya-punto, respectivamente (las soluciones de las variables $L_{i}$ para $i=1,2,3$ se han omitido por conveniencia). Note que en todos los casos la efectividad del tratamiento antirretroviral es incompleta, siendo $A=1800$ y $A=2000$ las que presentan menores niveles de carga viral $V$ durante el tiempo de simulación $\tau=1000$; en ambos casos, $u_{1}^{*}$ que es la efectividad de los ITI, está por encima de 0.4. Para los valores $A=2100$ y $A=2500$ se obtuvieron efectividades de los ITI por debajo de 0.4 y puede observarse que las poblaciones de células y partículas virales (carga viral) presentan variaciones amplias típicas de la infección activa por VIH, lo que implica que para estos valores de los ponderadores no se alcanzan efectividades que controlen la infección de manera satisfactoria. En las cuatro soluciones que se ilustran, la efectividad de los IP se encuentran en el rango $(0.15,0.35)$, el cual es muy bajo, pero responde al alto valor asignado a $B$.

Simulaciones del problema de contorno (14) variando el ponderador $B$ y manteniendo fijo a $A$, arrojan resultados muy semejantes; sin embargo, el cambio cualitativo de comportamiento que se evidencia en la Figura 7 para diferentes valores de $A$, conlleva a preguntar por el impacto que los ponderadores tienen en la efectividad de los tratamientos. En la Figura 8, en la izquierda, se han ilustrado 

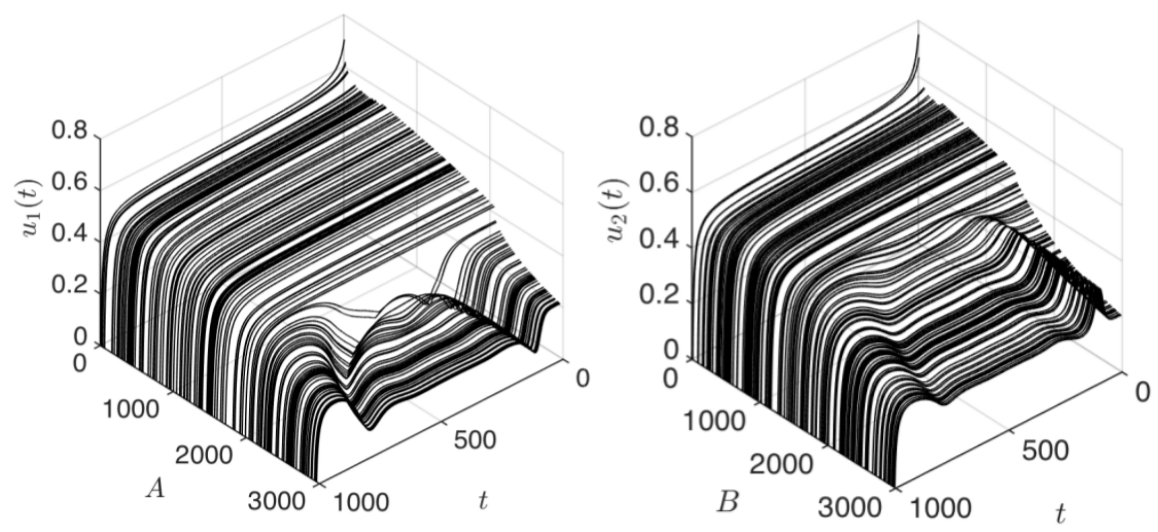

Figura 8: Se ilustran 150 curvas de $u_{1}^{*}$ y $u_{2}^{*}$ obtenidas de resolver numéricamente el problema de contorno (14). La simulación se hizo con los parámetros descritos en la Tabla 1. Izquierda: haciendo variar aleatoriamente parámetro $A$ en el rango $[0,3000]$ y con $B=3000$. Derecha: haciendo variar aleatoriamente parámetro $B$ en el rango $[0,3000]$ y con $A=3000$.

150 curvas de $u_{1}^{*}$ y $u_{2}^{*}$ en función del tiempo $t$ y haciendo variar aleatoriamente el parámetro $A$ en el rango $[0,3000]$ y con $B=3000$. La figura ilustra numéricamente como varían las efectividades del tratamiento al variar el ponderador, y ha permitido determinar que para $A>2000$ aproximadamente hay un cambio de comportamiento importante que puede observarse como una reducción significativa en la efectividad de ambos tratamientos y por el surgimiento de oscilaciones. Este hecho pone en evidencia la importancia que los costos (directos e indirectos) tienen sobre la efectividad que un esquema de tratamiento tiene en el futuro de la infección en un paciente. En particular se puede afirmar que para valores pequeños del ponderador se obtienen tratamientos más efectivos.

En la Figura 8, derecha, se ilustra una situación equivalente pero en la que se considera $A=3000$ y se ilustran 150 curvas de $u_{1}^{*}$ y $u_{2}^{*}$ en función del tiempo $t$ y haciendo variar aleatoriamente el parámetro $B$ en el rango $[0,3000]$. Como puede notarse, el comportamiento de las efectividades de medicamentos no presenta el cambio de comportamiento evidenciado en la variación de $A$.

\section{Conclusiones}

El modelo propuesto describe la dinámica de infección por VIH y permite concluir que el número básico de reproducción $R_{0}$ es especialmente importante para 
determinar el comportamiento futuro de la dinámica, en el sentido que reducciones del $R_{0}$ implican evoluciones más lentas de la infección. En particular el escenario $R_{0} \leq 1$ describe el caso en que la infección no prospera en el individuo, es decir, el paciente no resulta infectado con el virus tras enfrentar una situación de riesgo, este caso corresponde a un resultado meramente teórico, que según los autores podría describir situaciones en que la carga viral es llevada a niveles no detectables, sin embargo, debe motivar a futuras investigaciones al respecto y a una discusión más amplia.

Con el estudio del modelo sin tratamiento antirretroviral, y en particular del impacto de la tasa de saturación media del virus $k$, pudo observarse que incrementar $k$ tiene el efecto esperado de reducir la magnitud del $R_{0}$, lo que implica que tasas de saturación altas conllevan a menores niveles de viremia y un menor impacto en la población de células $T$. En ese sentido, conocer de manera más precisa la respuesta del virus frente a su propia densidad sería importante a la hora de estimar el comportamiento futuro de la infección por VIH y eventualmente para el establecimiento de esquemas de tratamiento.

Se ha formulado un umbral de control mediante la reducción de la tasa máxima de infección $\beta$ que puede ser usado como criterio para establecer si en el sistema se presenta un brote de infección o no; es decir, para valores de $\beta$ por debajo del umbral $\beta_{m}$ se tiene $R_{0}<1$ y para valores mayores se tiene $R_{0}>1$. En ese sentido, $\beta_{m}$ es un valor de bifurcación para el sistema dinámico estudiado. Un resultado similar puede obtenerse con cualquiera de los parámetros del modelo involucrados en $R_{0}$ y sus usos y aplicaciones dependerán del interés particular de quien modela.

Se ha mostrado analíticamente que los costos directos e indirectos de la aplicación del tratamiento (los ponderadores asociados a cada control), tienen un efecto significativo en los controles óptimos que se obtuvieron en el caso de la efectividad imperfecta. Numéricamente se pudo ilustrar ese impacto y se puede concluir que para valores altos de esos ponderadores, se obtiene una reducción significativa en la efectividad de ambos tratamientos. Este hecho pone en evidencia la importancia que los costos (directos e indirectos) tienen sobre la efectividad que un esquema de tratamiento tiene en el futuro de la infección en un paciente. Se puede afirmar que para valores pequeños de los ponderadores se obtienen tratamientos más efectivos.

El modelo con control antirretroviral considera la aplicación de un cóctel de medicamentos compuesto por ITI e IP. Los cócteles de medicamentos antirretrovirales durante los últimos años han sido la herramienta que la medicina moderna tiene para controlar la infección y mejorar la calidad de vida de los portadores del virus. El modelo hace posible apreciar cómo efectivamente los protocolos 
adecuados de intervención son los que reducen la tasa máxima de infección o la tasa de producción de nuevas partículas virales, hasta que se alcancen niveles no detectables de carga viral. Sin embargo, es evidente que tales protocolos deben ser estudiados y establecidos teniendo en cuenta los costos que implican su aplicación y los efectos secundarios que puedan generar en el paciente, situación que sólo puede ser determinada por un médico tratante que cuente con información detallada de la historia y hábitos del paciente.

El modelo permite establecer de manera aproximada el futuro de la infección en un paciente específico y de $\hat{A}$ «condiciones inmunológicas promedioÂ», siempre y cuando se cuente con la información precisa sobre el paciente; es decir, siempre que se conozcan los parámetros específicos. No es posible utilizar los resultados de este trabajo directamente sobre un paciente infectado, debe tenerse en cuenta que los modelos matemáticos son representaciones de la realidad que ayudan a comprender cómo funciona bajo un número significativo de supuestos.

\section{Agradecimientos}

El presente trabajo es financiado por la Universidad del Quindío, a través de la Vicerrectoría de Investigaciones. Proyecto de investigación No. 573.

\section{Referencias}

[1] Adams, B.M.; Banks, H.T.; Davidian, M.; Kwon, H.D.; Tran, H.T.; Wynne, S.N.; Rosenberg, E.S. (2005) "HIV dynamics: modeling, data analysis, and optimal treatment protocols", Journal of Computational and Applied Mathematics 184(1): 10-49.

[2] AIDS (2011) Guidelines for the Use of Antiretroviral Agents in HIV-1Infected Adults and Adolescents.

[3] Arhel, N. (2010) "Revisiting HIV-1 uncoating”, Retrovirology 7(96).

[4] Arnold, E.; Sarafianos, S.G. (2008) "Molecular biology: An HIV secret uncovered", Nature 453(7192): 169-170.

[5] Bairagi, N.; Adak, D. (2014) "Global analysis of HIV-1 dynamics with Hill type infection rate and intracellular delay", Applied Mathematical Modelling 38(21-22): 5047-5066.

[6] Bandyopadhyay, M.; Chattopadhyay, J. (2005) "Ratio-dependent predator-prey model: effect of environmental fluctuation and stability", Nonlinearity 18(2): 913-936. 
[7] Campos-Delgado, D. U.; Palacios, E. (2005) "Análisis y control de la dinámica del VIH-1", Universidad Autónoma de San Luis Potosí, Facultad de Ciencias.

[8] Cazelles, B.; Chau, N.P. (1997) "Using the Kalman filter and dynamic models to assess the changing HIV/AIDS epidemic", Mathematical Biosciences 140(2): 131-154.

[9] Chao, D. L.; Davenport, M. P.; Forrest, S.; Perelson, A. S. (2004) “A stochastic model of cytotoxic T cell responses", Journal of Theoretical Biology 228(2): 227-240.

[10] Cleary, S. M.; Mooney, G. H.; McIntyre, D. E. (2011) "Claims on health care: a decision-making framework for equity, with application to treatment for HIV/AIDS in South Africa", Health Policy and Planning 26(6): $464-470$.

[11] Culshaw, R. V.; Ruan, S.; Spiteri, R. J. (2004) "Optimal HIV treatment by maximising immune response”, Journal of Mathematical Biology 48(5): $545-562$.

[12] Dalal, N.; Greenhalgh, D.; Mao, X. (2008) "A stochastic model for internal HIV dynamics", Journal of Mathematical Analysis and Applications 341(2): 1084-1101.

[13] Del Valle, S.; Evangelista, A.M.; Velasco, M.C.; Kribs-Zaleta, C.M.; Schmitz, S.F.H. (2004) "Effects of education, vaccination and treatment on HIV transmission in homosexuals with genetic heterogeneity", Mathematical Biosciences 187(2): 111-133.

[14] Dinga, A.; Wub, H. (1999) "Relationships between antiviral treatment effects and biphasic viral decay rates in modeling HIV dynamics, Mathematical Biosciences 160(1): 63-82.

[15] Fleming, W.H.; Rishel, R. W. (1975) Deterministic and Stochastic Optimal Control. Springer-Verlag, New York.

[16] Gómez, M. (2008) “Comparación de tres estrategias de tamizaje para la prevención de la infección perinatal por VIH en Colombia: análisis de decisiones", Revista Panamericana de Salud Publica 24(4): 256-264.

[17] Gray, R.H.; Li, X.; Wawer, M.J.; Gange, S.J.; Serwadda, D.; Sewankambo, N.K.; Moore, R.; Wabwire-Mangen, F.; Lutalo, T.; Quinn, 
T.C. (2003) "Stochastic simulation of the impact of antiretroviral therapy and HIV vaccines on HIV transmission; Rakai, Uganda", AIDS 17(13): 1941-1951.

[18] Guo, H.; Li, M.Y. (2008) "Global dynamics of a staged-progression model with amelioration for infectious diseases", Journal of Biological Dynamics 2(2): 154-168.

[19] Haacker, M. (2002) Modeling the Macroeconomic Impact of HIV/AIDS. IMF Working Paper.

[20] Hackbusch, W. (1978) "A numerical method for solving parabolic equations with opposite orientations", Computing 20(3): 229-240.

[21] Hosseini, I.; Gabhann, F. (2012) "Multi-scale modeling of HIV infection in vitro and APOBEC3G-based anti-retroviral therapy", PLoS Computational Biology 8(2): 1-17.

[22] Huang, G.; Ma, W.; Takeuchi, Y. (2009) "Global properties for virus dynamics model with Beddington-DeAngelis functional response", Applied Mathematics Letters 22(11): 1690-1693.

[23] Jiang, D.; Liu, Q.; Shi, N.; Hayat, T.; Alsaedi, A.; Xia, P. (2017) "Dynamics of a stochastic HIV-1 infection model with logistic growth", Physica A: Statistical Mechanics and its Applications 469: 706-717.

[24] Joly, M.; Pinto, J. M. (2006) "Role of mathematical modeling on the optimal control of HIV-1 pathogenesis", AIChE Journal 52(3): 856-884.

[25] Joshi, H. R. (2002) "Optimal control of an HIV immunology model", Optimal Control Applications and Methods 23(4): 199-213.

[26] Kamina, A.; Makuch, R. W.; Zhao, H. (2001) "A stochastic modeling of early HIV-1 population dynamics", Mathematical Biosciences 170(2): 187-198.

[27] Khalil, H.K. (1996). Nonínear Systems. Prentice-Hall, New Jersey.

[28] Kirschner, D. (1996) "Using mathematics to understand HIV immune dynamics", Notices of the AMS 43(2): 191-202.

[29] Kirschner, D.; Webb, G.F. (1996) "A model for treatment strategy in the chemotherapy of AIDS", Bulletin of Mathematical Biology 58(2): 367-390. 
[30] Kirschner, D.E.; Webb, G.F. (1998) "Immunotherapy of HIV-1 infection”, Journal of Biological Systems 6(1): 71-83.

[31] Kirschner, D.E.; Chang, S.T.; Riggs, T.W.; Perry, N.; Linderman, J.J. (2007) "Toward a multiscale model of antigen presentation in immunity", Immunological Reviews 216(1): 93-118.

[32] Kouyos, R.D.; Althaus, C.L.; Bonhoeffer, S. (2006) "Stochastic or deterministic: what is the effective population size of HIV-1?", Trends in Microbiology 14(12): 507-511.

[33] La Salle, J.P. (1976) The Stability of Dynamical Systems. Society for Industrial and Applied Mathematics, Philadelphia.

[34] Ladino, L.M.; Valverde, J.C. (2012) "Population dynamics of a two-stage species with recruitment", Mathematical Methods in the Applied Sciences 36(6): 722-729.

[35] Lenhart, S.; Workman, J.T. (2007) Optimal Control Applied to Biological Models. Chapman \& Hall/CRC, United States.

[36] Li, D.; Ma, W. (2007) "Asymptotic properties of a HIV-1 infection model with time delay", Journal of Mathematical Analysis and Applications 335(1): 683-691.

[37] Mubayi, A.; Zaleta, C.K.; Martcheva, M.; Castillo-Chávez, C. (2010) "A cost-based comparison of quarantine strategies for new emerging diseases", Mathematical Biosciences and Engineering 7(3): 687-717.

[38] Nelson, P.W.; Murray, J D.; Perelson, A.S. (2000) "A model of HIV1 pathogenesis that includes an intracellular delay", Mathematical Biosciences 163(2): 201-215.

[39] Núñez, C.A.; Aguilar, S.; Fernández, V.H. (2001) Exclusión Social y VIHSIDA en Guatemala. Sistema de Naciones Unidas, Guatemala.

[40] Oliva-Moreno, J.; López-Bastida, J.; Serrano-Aguilar, P.; Perestelo-Pérez, L. (2010) "Determinants of health care costs of HIV-positive patients in the Canary Islands, Spain", The European Journal of Health Economics 11(4): 405-412.

[41] Orellana, J.M. (2011) "Optimal drug scheduling for HIV therapy efficiency improvement", Biomedical Signal Processing and Control 6(4): 379-386. 
[42] Perelson, A.S. (2002) "Modelling viral and immune system dynamics", Nature Reviews Immunology 2(1): 28-36.

[43] Perelson, A.S.; Kirschner, D.E.; De Boer, R. (1993) "Dynamics of HIV infection of CD4+ T cells", Mathematical Biosciences 114(1): 81-125.

[44] Perelson, A.S.; Nelson, P.W. (1999) "Mathematical analysis of HIV-1 dynamics in vivo", SIAM Review 41(1): 3-44.

[45] Raffi, F.; Rachlis, A.; Stellbrink, H.J.; Hardy, W.D.; Torti, C.; Orkin, C.; Bloch, M.; Podzamczer, D.; Pokrovsky, V.; Pulido, F.; Almond, S.; Margolis, D.; Brennan, C.; Min, S. (2013) "Once-daily dolutegravir versus raltegravir in antiretroviral-naive adults with HIV-1 infection: 48 week results from the randomised, double-blind, non-inferiority SPRING-2 study", The Lancet 381(9868): 735-743.

[46] Revilla, T.; García-Ramos, G. (2003) "Fighting a virus with a virus: a dynamic model for HIV-1 therapy", Mathematical Biosciences 185(2): 191-203.

[47] Ribeiro, R. M.; Bonhoeffer, S. (1999) "A stochastic model for primary HIV infection: optimal timing of therapy", AIDS 13(3): 351-357.

[48] Schmitz, H. (2000) "Effects of treatment or/and vaccination on HIV transmission in homosexuals with genetic heterogeneity", Mathematical Biosciences 167(1): 1-18.

[49] Shim, H.; Han, S.J.; Chung, C.C.; Nam, S.W.; Seo, J.H. (2003) “Optimal scheduling of drug treatment for HIV infection: continuous dose control and receding horizon control", International Journal of Control, Automation and Systems 1(3): 282-288.

[50] Srivastava, P.K.; Chandra, P. (2010) "Modeling the dynamics of HIV and CD4+ T cells during primary infection", Nonlinear Analysis: Real World Applications 11(2): 612-618.

[51] Stengel, R.F. (2008) "Mutation and control of the human immunodeficiency virus", Mathematical Biosciences 213(2): 93-102.

[52] Tan, W.Y.; Byers, R.H. (1993) "A stochastic model of the HIV epidemic and the HIV infection distribution in a homosexual population", Mathematical Biosciences 113(1): 115-143. 
[53] Taylor, J.M.; Cumberland, W.G.; Sy, J.P. (1994) "A stochastic model for analysis of longitudinal AIDS data", Journal of the American Statistical Association 89(427): 727-736.

[54] Toro, H.D.; Caicedo, A.G.; Bichara, D.; Lee, S. (2014) "Role of Active and Inactive Cytotoxic Immune Response in Human Immunodeficiency Virus Dynamics", Osong Public Health and Research Perspectives 5(1): $3-8$.

[55] Toro, H.D.; Londoño, C.A.; Trujillo, C.A. (2014) "Modelo de simulación para la infección por VIH y su interacción con la respuesta inmune citotóxica”, Revista de Salud Pública 16(1): 114-127.

[56] Toro-Zapata, H.D.; Roa-Vásquez, E.; Mesa-Mazo, M.J. (2017) "Modelo estocástico para la infección con VIH de las células T CD4+ del sistema inmune", Revista de Matemática: Teoría y Aplicaciones 24(2): 287-313.

[57] Trujillo-Salazar, C.A.; Toro-Zapata, H.D. (2014) "Análisis teórico de la transmisión y el control del VIH/SIDA en un centro de reclusión", in: D. Tarzia (Ed.) VII Italian-Latin American Conference on Industrial and Applied Mathematics, Universidad Austral, Facultad de Ciencias Empresariales, Argentina: 17-26.

[58] Trujillo-Salazar, C.A.; Toro-Zapata, H.D. (2015) "Simulation model for AIDS dynamics and optimal control through antiviral treatment", in: G. Tost \& O. Vasilieva (Eds.) Analysis, Modelling, Optimization, and $\mathrm{Nu}$ merical Techniques, ICAMI, San Andres Island, Colombia: 257-270.

[59] Wandeler, G.; Keiser, O.; Hirschel, B.; Günthard, H.F.; Bernasconi, E.; Battegay, M.; Clerc, O.; Vernazza, P.L.; Furrer, H. (2011) "A comparison of initial antiretroviral therapy in the Swiss HIV Cohort Study and the recommendations of the International AIDS Society-USA", PLoS One 6(12): $1-8$.

[60] Wang, J.; Guo, M.; Liu, X.; Zhao, Z. (2016) “Threshold dynamics of HIV-1 virus model with cell-to-cell transmission, cell-mediated immune responses and distributed delay", Applied Mathematics and Computation 291: 149-161.

[61] Wang, L. (2011) "Global mathematical analysis of an HIV-1 infection model with holling Type-II incidence", Communications in Applied Analysis 15(1): 47-56. 
[62] Zaric, G.S.; Bayoumi, A.M.; Brandeau, M.L.; Owens, D.K. (2008) "The cost-effectiveness of counseling strategies to improve adherence to highly active antiretroviral therapy among men who have sex with men", Medical Decision Making 28(3): 359-376. 